\title{
IGNITION OF WET WOOD PARTICLES IN THE STREAM OF HIGH-TEMPERATURE GASES
}

\author{
S. V. Syrodoy ${ }^{1, *}, N$. Y. Gutareva ${ }^{1}$, and $K$. A. Bugaeva ${ }^{1}$ \\ ${ }^{1}$ National Research Tomsk Polytechnic University, 634050 Tomsk, Russia
}

\begin{abstract}
The problem of wet wood ignition of particles in a hightemperature gas has been solved numerically in the framework of a quasifrontal model of evaporation. The basic characteristics of the ignition has been shown in the article. The influence of the different parameters on the ignition conditions has been shown in this work.
\end{abstract}

\section{Introduction}

Formation of a large amount of wood waste $[1,2]$, which are formed at preparation and processing of wood, is the most urgent issue [3, 4] of wood industry for today. This waste includes slab, bark, sawdust, shavings, wood dust, wood chips. Storage and warehousing of them are almost impossible for a number of reasons, main of which is high fire hazard and explosion of timber $[5,6]$. For this reason, the most promising and cost-effective way to dispose of "secondary" timber is its implementation (as fuel) to the overall balance of thermal and power generation [7-10]. It should be added that the use of wood waste as a raw material for the boiler units has a number of significant advantages [11-15] over traditional (oil, gas, coal) fuels. Firstly it is a significant expansion of the resource base of modern boilers [11] and the possibility of autonomous power supply [12] distant (from the main settlements) areas (places of lumbering or extraction of oil). The important advantage is the fact that the wood is the only renewable fuel [13] while reserves of the conventional fuels (oil and coal) are limited. It should also be noted environmental friendliness of wood [14]. We can see almost no sulfur in its composition [15], so there is practically no sulfur oxide in burning products, which generated during the combustion of wood. $\mathrm{CO}_{2}$ concentration can be minimized through better choice of the design characteristics of the flue boilers devices [16]. It also worth noting that $0.5 \%$ to $3 \%$ of ash is formed by burning the timber [17], while for some coals, this figure may reach $50 \%$ [18]. Accordingly, it can be said that the creation of energy efficiency and perspective from ecology point of view boiler units working on wood waste, is one of the most perspective trends in modern energy technology [19].

However it is known that the wood (in most cases) is a highly-watered fuel [20, 21]. Accordingly, an essential stage of thermal treatment of the particle to the fire is the process of evaporation.

It should be noted that the mathematical modeling of phase transformation (e.g. evaporation), is one of the most difficult problem. This is due to the fact that in conditions

\footnotetext{
* Corresponding author: ssyrodoy@yandex.ru
} 
of high heat moisture evaporation occurs in a narrow (much less than the linear size of the particle) constantly moving area ("front" of evaporation). The latter fact is complicated by high water evaporation endothermic effect (up to $2.5 \mathrm{MJ} / \mathrm{kg}$ ).

By now quite a large number of [22-25] models of the process dehydration of highlywatered porous particles have been designed. However, most of them are based on some assumptions, which can significantly simplify the procedure of modeling. For example, the temperature equilibrium [22] on the partition border of the system "water-vapor" or application method of moisture-potential [23]. Models of [24, 25] "drying" of wet timber are based on the concept of volume phase transition of the distribution in space. The most complete evaporation process describes the model [26], which is based on the idea that a phase transition occurs in the front, on the border of the system "water-vapor". And the temperature depends on the rate of evaporation. Numerical modeling of the dehydration of the fuel particle has been realized by using the method of time step accumulation [27].

However, it is worth noting that this approach is difficult realized in a high-temperature heating at the decision the problem of ignition (processes of evaporation, pyrolysis and ignition occur together), and can lead to significant inaccuracies of calculations. Accordingly, the mathematical modeling of heat and mass transfer processes in the ignition highly-watered fuels (such as wet wood), in the conditions of high temperature heating at the joint main of basic thermal treatment processes (water evaporation, pyrolysis of the organic part of the fuel), is an urgent (unresolved to date) problem.

The purpose is the mathematical modeling of the ignition of damp wood particles in high-temperature heating in the gaseous environment.

\section{Formulation of the problem}

The model of the ignition process has been accepted. At the initial time $(\tau=0)$ spherical wet wood particle gets to a stream of high-temperature environment. The process of fast water evaporation begins as a result of intensive heating. The front of evaporation moves away from the surface into the interior of the particle. A porous layer with a high thermal resistance is formed. Further heating initiates thermal decomposition of wood, and volatile substances are allocated. Vapor-gas mixture is formed near the surface. It ignites at critical values of temperature and concentrations. The period of time from the start of the heat exposure to the moment of ignition is the ignition delay time $\left(\mathrm{t}_{\mathrm{ign}}\right)$.

The mathematical formulation of the problem, which corresponds to the above physical model, has been formulated as a system of differential equations in partial derivatives:

- the energy equation for the wood particle:

$$
\begin{aligned}
C p_{w}(T) \rho_{w}(T) \frac{\partial T_{1}}{\partial t}=\frac{1}{r^{2}} \frac{\partial}{\partial r}\left[r^{2} \cdot \lambda_{w} \cdot \frac{\partial T_{1}}{\partial r}\right] \pm \sum_{i=1}^{n} Q_{i} \cdot W_{i}-\frac{Q_{e} \cdot W_{e}}{h_{s p}} \\
0<r<r_{0}
\end{aligned}
$$

Where: $\sum_{i=1}^{n} Q_{i} \cdot W_{i}=Q_{t d} \cdot W_{t d}+Q_{c} \cdot W_{c}$

- the energy equation for the gas environment:

$$
\begin{gathered}
C p_{g} \rho_{g} \frac{\partial T_{2}}{\partial t}=\frac{\lambda_{g}}{r^{2}} \frac{\partial}{\partial r}\left[r^{2} \cdot \frac{\partial T_{2}}{\partial r}\right]+Q_{b} \cdot W_{b} \\
r_{0}<r<r_{g}
\end{gathered}
$$


- the equation of diffusion of pyrolysis products in the gas phase:

$$
\begin{gathered}
\rho_{g} \frac{\partial C_{1}}{\partial t}=\frac{D_{1} \cdot \rho_{g}}{r^{2}} \frac{\partial}{\partial r}\left[r^{2} \cdot \frac{\partial C_{1}}{\partial r}\right]-W_{b} \\
r_{0}<r<r_{g}
\end{gathered}
$$

- the equation of diffusion of water vapor in the environment:

$$
\begin{array}{r}
\rho_{g} \frac{\partial C_{2}}{\partial t}=\frac{D_{2} \cdot \rho_{g}}{r^{2}} \frac{\partial}{\partial r}\left[r^{2} \cdot \frac{\partial C_{2}}{\partial r}\right] \\
r_{0}<r<r_{g}
\end{array}
$$

Mass rate of evaporation $\left(\mathrm{W}_{\mathrm{e}} \mathrm{kg} /\left(\mathrm{m}^{2} \cdot \mathrm{s}\right)\right)$ has been calculated as in [28]:

$$
W_{e}=W_{0} \cdot \exp \left(\frac{Q_{e} \cdot \mu \cdot\left(T_{e}-T_{f}\right)}{R \cdot T_{f} \cdot T_{e}}\right) \text {. }
$$

The coordinate evaporation border has been found from the expression:

$$
r_{F}=r_{0}-\int_{0}^{\tau} u_{F} d \tau
$$

Where $u_{f}=W_{e} / \rho_{w t}$ - linear rate of advance of the evaporation front, $\mathrm{m} / \mathrm{s}$.

Upon reaching the surface of the particle conditions $T_{s} \geq T_{s t d}\left(T_{s}-\right.$ surface temperature, $\mathrm{T}_{\text {std }}$ - temperature of thermal decomposition start) decomposition of the organic part of the fuel with the release of volatiles starts in the particle. The process is described by the thermal decomposition of chemical kinetics:

$$
\frac{\partial \eta(r, t)}{\partial t}=[1-\eta(r, t)] \cdot k_{t d} \cdot \exp \left(-\frac{E_{t d}}{R \cdot T(r, t)}\right)
$$

Pyrolysis rate has been calculated using the expression:

$$
W_{t d}=[1-\eta(r, t)] \cdot k_{t d} \cdot \rho(t) \cdot \exp \left(-\frac{E_{t d}}{R \cdot T(r, t)}\right)
$$

In the "near-wall" area of the particle this reaction occurs: $\mathrm{CH}_{4}+\mathrm{O}_{2}=\mathrm{CO}_{2}+\mathrm{H}_{2} \mathrm{O}+55546$ $\mathrm{kJ} / \mathrm{kg}$. The rate of it has been calculated from the mathematical expression of the Arrhenius law:

$$
W_{b}=\left(1-C_{1}-C_{2}\right) \cdot C_{1} \cdot k_{b} \cdot \rho_{g} \cdot \exp \left[-\frac{E_{b}}{R \cdot T(r, t)}\right]
$$

Oxidant concentration has been determined from the material balance of the system "oxidizer - water vapor — volatile":

$$
C_{1}+C_{2}+C_{3}=1
$$


It is assumed that part of the combustible solid residue is mainly composed of carbon. Accordingly, the reaction occurs at the surface of the wood particle $\mathrm{C}+\mathrm{O}_{2}=\mathrm{CO}_{2}+18560$ $\mathrm{kJ} / \mathrm{kg}$. The rate of this reaction has been calculated from the expression:

$$
W_{c}=k_{c} \cdot \rho_{w} \cdot \exp \left[-\frac{E_{c}}{R \cdot T(r, t)}\right]
$$

The system of equations (1) - (11) has been solved with the boundary conditions:

$$
\begin{aligned}
& 0<r<r_{0}, T(r, 0)=T_{0}, r_{0}<r<r_{g}, T(r, 0)=T_{e}, \eta(r, 0)=\eta_{0} . \\
& \frac{\partial T(0, t)}{\partial r}=0 \\
& \frac{\partial T^{2}\left(r_{g}, t\right)}{\partial r^{2}}=0 \\
& \frac{\partial C_{1}^{2}\left(r_{g}, t\right)}{\partial r^{2}}=0 \\
& \frac{\partial C_{1}\left(r_{0}, t\right)}{\partial r}=\frac{W_{t d} \cdot r_{0}}{\rho_{g} \cdot D_{1}} \\
& \frac{\partial C_{2}\left(r_{0}, t\right)}{\partial r}=\frac{W_{e} \cdot r_{0}}{\rho_{g} \cdot D_{1}} \\
& \frac{\partial C_{2}^{2}\left(r_{g}, t\right)}{\partial r^{2}}=0
\end{aligned}
$$

The boundary condition of the fourth kind is performed at the interface of the system "wood particle - environment":

$$
\begin{aligned}
\left.\lambda_{w} \frac{\partial T_{1}}{\partial r}\right|_{r=r_{0}-0} & =\left.\lambda_{g} \frac{\partial T_{2}}{\partial r}\right|_{r=r_{0}+0} \\
T\left(r_{0} ; t\right) & =T\left(r_{0} ; t\right)
\end{aligned}
$$

The designations: $\mathrm{T}_{0}-$ the initial temperature of the particle, $\mathrm{K} ; \mathrm{T}_{\mathrm{e}}-$ ambient temperature, $\mathrm{K} ; \eta_{0}-$ the initial value of the parameter of burnout; $\sum_{i=1}^{n} Q_{i} \cdot W_{i}-$ the complex, which takes into account the total thermal effect of the process of pyrolisis and ignition of the organic part of fuel, $\mathrm{W} / \mathrm{m}^{3} ; Q_{b} \cdot W_{b}$ - the complex, which takes into account the thermal effect of thermochemical interaction the pyrolysis products with the oxidant, $\mathrm{W} / \mathrm{m}^{3} ; Q_{e} \cdot W_{e}$ - the complex, which takes into account the thermal effect of water evaporation, $\mathrm{W} / \mathrm{m}^{2} ; Q_{t d} \cdot W_{t d}$ - the complex, which takes into account the thermal effects in evaporation of water, $\mathrm{W} / \mathrm{m}^{3} ; Q_{c} \cdot W_{c}$ - the complex, which takes into account thermal effect of thermochemical interaction the organic part of the fuel with the oxidant, $\mathrm{W} / \mathrm{m}^{3} ; k_{t d}-$ pre-exponential factor of thermal decomposition reaction, $1 / \mathrm{s} ; k_{b}-$ pre-exponential factor of the reaction of combustible components, $1 / \mathrm{c} ; C_{1}-$ concentration of combustible components; $C_{2}$ - concentration of water vapor; $E_{t d}-$ the activation energy of the thermal 
decomposition reaction, $\mathrm{J} /($ mole $\cdot \mathrm{K}) ; E_{b}-$ the activation energy of the oxidation reaction of the combustible components, $\mathrm{J} /($ mole $\cdot \mathrm{K}) ; \eta(\mathrm{r}, \mathrm{t})$ - burnout parameter; $T_{f}$ - water temperature corresponding to the freezing point, $\mathrm{K} ; \mu$ - the molar mass of water, $\mathrm{kg} / \mathrm{mole}$; $\mathrm{R}$ - universal gas constant, $\mathrm{J} /($ mole $\cdot \mathrm{K}) ; W_{0}-$ mass rate of water evaporation at the temperature $T_{f} \mathrm{~kg} /\left(\mathrm{m}^{2} \cdot \mathrm{s}\right) ; Q_{e}$ - the thermal effect of water evaporation, $\mathrm{J} / \mathrm{kg} ; Q_{c}-$ the thermal effect of the carbon ignition reaction, $\mathrm{J} / \mathrm{kg} ; Q_{t d}-$ thermal effect of thermal decomposition reaction, $\mathrm{J} / \mathrm{kg} ; Q_{b}$ - thermal effect of volatile ignition reaction, $\mathrm{J} / \mathrm{kg} ; T_{e}$ - temperature of the boundary of evaporation, $\mathrm{K} ; \lambda_{\mathrm{w}}$ - thermal conductivity coefficient of wood, $\mathrm{W} /(\mathrm{m} \cdot \mathrm{K}) ; \lambda_{\mathrm{g}}$ - thermal conductivity coefficient of external environment, $\mathrm{W} /(\mathrm{m} \cdot \mathrm{K})$; $C p_{w}$ - heat capacity of wood, $\mathrm{J} /(\mathrm{kg} \cdot \mathrm{K}) ; C p_{g}$ - heat capacity of external environment, $\mathrm{J} /(\mathrm{kg} \cdot \mathrm{K}) ; \rho_{\mathrm{w}}$ - wood density, $\mathrm{kg} / \mathrm{m} 3 ; \rho_{\mathrm{g}}$ - environment density, $\mathrm{kg} / \mathrm{m} 3 ; \mathrm{r}_{0}-$ particle radius, $\mathrm{m} ; \mathrm{r}_{\mathrm{g}}$ - outer radius of gas area, $\mathrm{m} ; h_{s p}-$ spreading parameter of evaporation front.

The thermal conductivity, heat capacity and density of the wet and "dehydrated" parts of fuel have been calculated based on the volume fractions of the major components:

$$
\begin{array}{cl}
\lambda_{1}=\varphi_{4} \lambda_{4}+\varphi_{5} \lambda_{5} & \lambda_{2}=\varphi_{5} \lambda_{5}+\varphi_{6} \lambda_{6} \\
\mathrm{Cp}_{1}=\varphi_{4} \mathrm{C}_{4}+\varphi_{5} \mathrm{C}_{5} & \mathrm{Cp}_{2}=\varphi_{5} \mathrm{C}_{5}+\varphi_{6} \mathrm{C}_{6} \\
\rho_{1}=\varphi_{4} \rho_{4}+\varphi_{5} \rho_{5} & \rho_{2}=\varphi_{5} \rho_{5}+\varphi_{6} \rho_{6}
\end{array}
$$

Where: $\varphi$ - volume fraction of the fuel component: 4 - water; 5 - wood; 6 - water vapor.

\section{Results}

The figure 1 shows the time of ignition delay of wood particles, depending on the ambient temperature. The analysis of the graphs shows that ambient temperature rise reduces the ignition delay time. It is worth noting the non-linear character of the graphs (1)-(3). It demonstrates the essential influence of the complex co-occurring physical and chemical processes during the thermal treatment. So after analyzing the dependences $\tau_{\text {ign }}(T)$ of particles diameter $\delta=0.5 \cdot 10^{-3} \mathrm{~m}-\delta=5 \cdot 10^{-3} \mathrm{~m}$ it is possible to note significant differences of ignition delay times at ambient temperature $T_{e}=800 \mathrm{~K}$. The last suggests a fairly high degree of influence on the process of evaporating moisture ignition.

Figure 2 shows the dependence of the delay time of ignition of wood particles with a diameter $\delta=1 \cdot 10^{-3} \mathrm{~m}$ on a fraction of moisture in the structure of fuel. The analysis of the dependences shows that the increase of fuel moisture leads to significant ignition delay (almost in 2 times). This is because high water content in the wood heat removal is greatly increased due to evaporation of moisture and thus complete "dehydration" of the particle occurs much longer.

Figure 3 shows the temperature distribution in the system of "fuel particles — gas environment" at the moment of ignition. The analysis of dependency $\mathrm{T}(\mathrm{r})$ indicates that the ignition of wood particles under conditions of relatively low ambient temperature (Te $<1000 \mathrm{~K}$ ) takes place only after completely removing moisture. In other words, it requires deeper heating of the main fuel layer. Meanwhile in the case of high-temperature heating ( Te $>1000 \mathrm{~K}$ ) wood particles can ignite before their complete dehydration. It is possible to note the characteristic bend at the graph 1 (figure 3). It shows the interface of the system "wet particle - dry wood." It can be concluded that the subsequent burning of such flooded fuel will significantly differ from the oxidation of dry wood particles. 


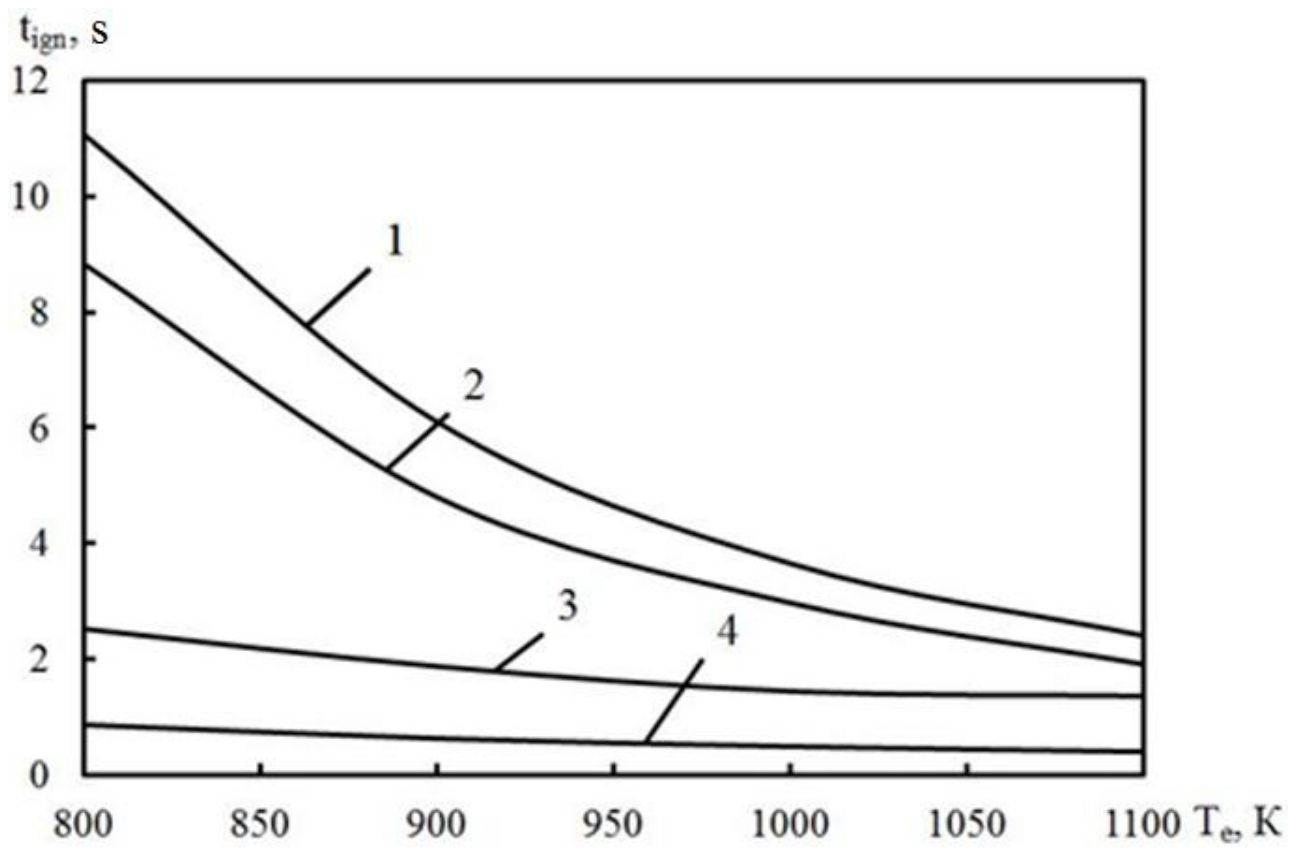

Fig. 1. The dependence of the ignition delay times of wood particles (humidity $10 \%$ ) the ambient temperature at a rate $(\delta)$ particle: $1-\delta=5 \cdot 10^{-3} \mathrm{~m} ; 2-\delta=3 \cdot 10^{-3} \mathrm{~m} ; 3-\delta=1 \cdot 10^{-3} \mathrm{~m} ; 4-\delta=0.5 \cdot 10^{-3} \mathrm{~m}$.

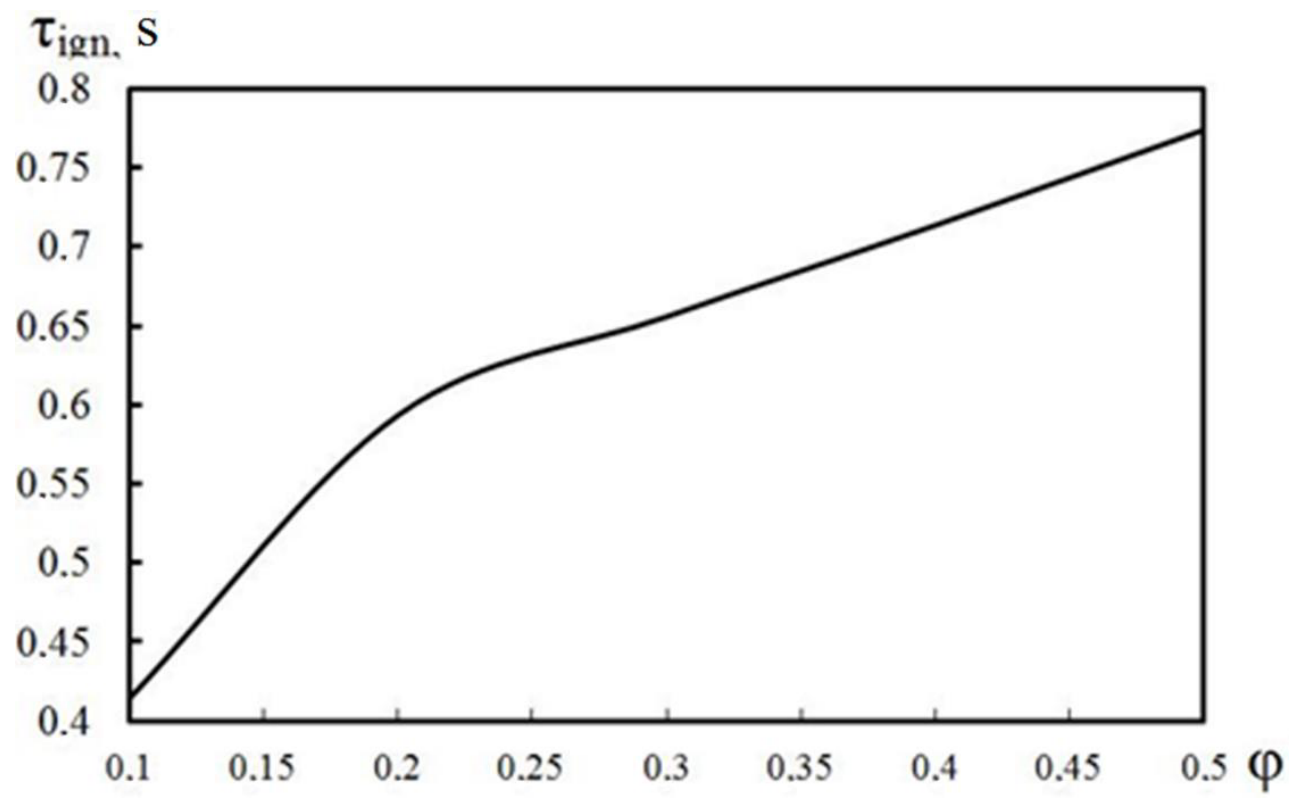

Fig. 2. The dependence of the ignition delay times of wood particles on a fraction of moisture in its structure.

\section{Conclusion}

Delay times of the ignition of wet wood particles have been set with varying sizes ranging from $\delta=0.5 \cdot 10^{-3} \mathrm{~m}$ to $\delta=5 \cdot 10^{-3} \mathrm{~m}$ in different heat transfer conditions based on the results 
of mathematical modeling. It is established that the co-occurrence of the complex of thermal treatment processes (slow heating, water evaporation, thermal decomposition of the organic part of the fuel, gas-phase ignition of volatiles) has a significant impact on characteristics and conditions of the ignition.

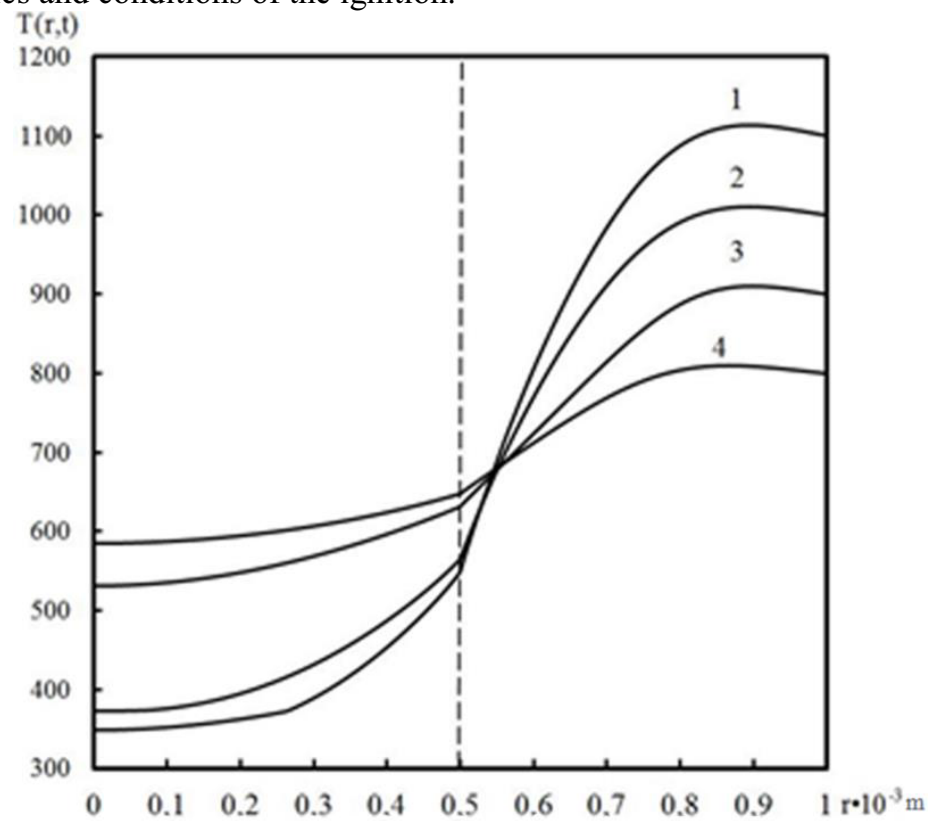

Fig. 3. The temperature distribution along the radius in the system "wood particle - gas environment" diameter $\delta=1 \cdot 10^{-3} \mathrm{~m}$ at ambient temperatures: $1-\mathrm{T}_{\mathrm{c}}=1100 \mathrm{~K} ; 2-\mathrm{T}_{\mathrm{c}}=1000 \mathrm{~K} ; 3-$ $\mathrm{T}_{\mathrm{c}}=900 \mathrm{~K} ; 4-\mathrm{T}_{\mathrm{c}}=800 \mathrm{~K}$.

According to the results of the numerical experiment, two different modes of ignition of wood particles have been installed - a high-temperature $(\mathrm{Te}>1000 \mathrm{~K})$ and low temperature $(\mathrm{Te} \leq 1000 \mathrm{~K})$. The ignition occurs only after complete dehydration of the main layer of fuel, in the case of ignition of wood particles in a medium with an oxidant temperature $\mathrm{Te}<1000 \mathrm{~K}$. Upon heating wood particles in the medium with ET $>1000 \mathrm{~K}$, ignition can occur before the complete removal of moisture. It is obvious that the subsequent combustion under continuing evaporation will substantially differ from the oxidation of the same (size and composition of the component), but dry particles.

\section{Acknowledgments}

The work at the field of modeling of heat and mass transfer processes near boundary between two layers was supported by the scientific schools grant NSH-7538-2016.8.

\section{References}

1. E. Ratajczak, G. Bidzińska, A. Szostak., M. Herbeć, Resour., Conserv. Recycl. 97 (2015)

2. N.S.L. Srivastava, S.L Narnaware, J.P. Makwana, S.N. Singh, S. Vahora, Renewable Energy 68 (2014)

3. J. F. Eshun, J. Potting, R. Leemans, J. Cleaner Prod. 26 (2012) 
4. E. T. Acquah, C. Whyte, Office of Sustainable Development, USAID Africa Bureau 139 (1998)

5. M. van Blijderveen, E. A. Bramer, G. Brem, Waste management 32, 9 (2012)

6. G. Hehar, O. Fasina, S. Adhikari, J. Fulton, Fuel Processing Technology 127 (2014)

7. H. Athari, S. Soltani, M. A. Rosen, S. M. S. Mahmoudi, T. Morosuk, Renewable Energy 92 (2016)

8. A.T. Thattai, V. Oldenbroek, L. Schoenmakers, T. Woudstra, P.V. Aravind, Appl. Energy 168 (2016)

9. P. C. Kuo, W. Wu, Energy Convers. Manage. 111 (2016)

10. P. C. Kuo, W. Wu, Chem. Eng. Sci. 142 (2016)

11. A. Favero, E. Massetti, Resource and Energy Economics 36, 1 (2014)

12. A.M. Hendricks, J.E. Wagner, T.A. Volk, D.H. Newman, Biomass and Bioenergy 88 (2016)

13. G.M.J. Herbert, A.U. Krishnan, Renewable Sustainable Energy Rev. 59 (2016)

14. M.C. Heller, G.A. Keoleian, M.K. Mann, T.A. Volk, Renewable Energy 29, 7 (2004)

15. C.A. Balaras, K. Droutsa, E. Dascalaki, S. Kontoyiannidis, Energy and buildings 37, 5 (2005)

16. C. Yu, L. Li, L. Zeng, Z. Tang, Powder Technol. 254 (2014)

17. D.E. Priyanto, S. Ueno, N. Sato, H. Kasai, T. Tanoue, H. Fukushima, Fuel 174 (2016)

18. J. He, M. Tan, R. Zhu, Y. Zhao, P. Hong, Y. Jiang, Fuel 172 (2016)

19. C. Li, C. Gillum, K. Toupin, B. Donaldson, Energy Convers. Manage. 103 (2015)

20. Y. Ding, C. Wang, S. Lu, Energy Convers. Manage. 98 (2015)

21. W.C.R. Chan, M. Kelbon, B.B. Krieger, Fuel 64, 11 (1985)

22. S.L. Mitchell, M. Vynnycky, Journal of Computational and Applied Mathematics 300 (2016)

23. F.R.G.B. Silva, G. Gonçalves, M.K. Lenzi, E.K. Lenzi, Int. J. Heat Mass Transfer 63 (2013)

24. V. Zadin, H. Kasemägi, V. Valdna, S. Vigonski, M. Veske, A. Aabloo, Applied Mathematics and Computation 267 (2015)

25. M.V. Belleghem, H.J. Steeman, M. Steeman, A. Janssens, M.D. Paepe, Building and Environment 45, $11(2010)$

26. S.V. Syrodoy, G.V. Kuznetsov, V.V. Salomatov, Thermal Engineering 62, 10 (2015)

27. S.V. Syrodoi, G.V. Kuznetsov, V.V. Salomatov, Solid Fuel Chem. 49, 6 (2015)

28. S.V. Syrodoy, V.V. Salomatov, N.Y. Gutareva, EPJ Web Conf. 76, Article Number 01018 (2014)

29. I.I. Markov, About the mechanism of evaporation at the interface of two media / I.I. Mark, A.A. Khashchenko, O.V. Evening, the Russian Defense Ministry, SKGTU, North-Caucasian branch of Technological Sciences. Collection of Scientific Works, A series "Physic-chemical, Stavropol (2004) 